\title{
Doppler weather radar based nowcasting of cyclone Ogni
}

\author{
Soma Sen Roy ${ }^{1, *}$, V Lakshmanan ${ }^{2}$, S K Roy Bhowmik ${ }^{1}$ and S B Thampi ${ }^{3}$ \\ ${ }^{1}$ India Meteorological Department, Lodi Road, New Delhi 110 003, India. \\ ${ }^{2}$ National Severe Storms Laboratory 83 University of Oklahoma, Norman, Oklahoma 73069, USA. \\ ${ }^{3}$ Doppler Weather Radar Station, India Meteorological Department, Chennai, India. \\ *e-mail: somasenroy@yahoo.com
}

In this paper, we describe offline analysis of Indian Doppler Weather Radar (DWR) data from cyclone Ogni using a suite of radar algorithms as implemented on NEXRAD and the advanced algorithms developed jointly by the National Severe Storms Laboratory (NSSL) and the University of Oklahoma. We demonstrate the applicability of the various algorithms to Indian radar data, the improvement in the quality control and evaluate the benefit of nowcasting capabilities in Indian conditions. New information about the tropical cyclone structure, as derived from application of the algorithms is also discussed in this study.

Finally, we suggest improvements that could be made to the Indian data collection strategies, networking and real-time analysis. Since this is the first study of its kind to process and utilize DWR data in a tropical climate, the suggestions on real-time analysis and data collection strategies made in this paper, would in many cases, be beneficial to other countries embarking on DWR network modernization programs.

\section{Introduction}

India is one of the most natural hazard-prone countries in the world, with floods, drought, and landslides being a regular threat to millions of its citizens every year. Most of the Indian landmass is prone to several natural disasters, with severe cyclones affecting the east and west coasts, largescale flooding in the major river systems such as Ganges, Brahmaputra, etc.

To address issues of disaster management in India, an Indo-US collaborative project for improvement and modernization of the hydrometeorological forecasting and early warning system in India was formulated (during 2003-2008) as a part of the Government of India (GOI) US Aid for International Development (USAID) Disaster Management Support Project (DMSP). Processing of Indian Doppler Weather Radar (DWR) data for nowcasting application under the sub-project Local Severe Storms and Flash
Floods was one component of this collaborative project.

IMD has recently started upgrading its old analog radar network with a denser network of DWRs. IMD has so far installed four S-Band DWRs manufactured by Gematronik Corporation (Model: Meteor 1500S) at Chennai (2002), Kolkata (2003), Machilipatnam (2004) and Visakhapatnam (2006) replacing the old generation S-Band cyclone detection radars at these stations. IMD has also installed one indigenously built DWR at Sriharikota in 2004. Figure 1 shows the current S-Band Doppler Weather Radar network in India. In addition to the current deployment of S-Band radars on the coast, there are plans to install more such radars inland (nearly 50 more radars) for utilization in severe storm forecasting and airport weather warnings.

The observational studies based on the Indian DWR graphics products, generated at the DWR sites, are reported by several authors (Sinha and

Keywords. Doppler weather radar observations; nowcasting; tropical cyclone. 


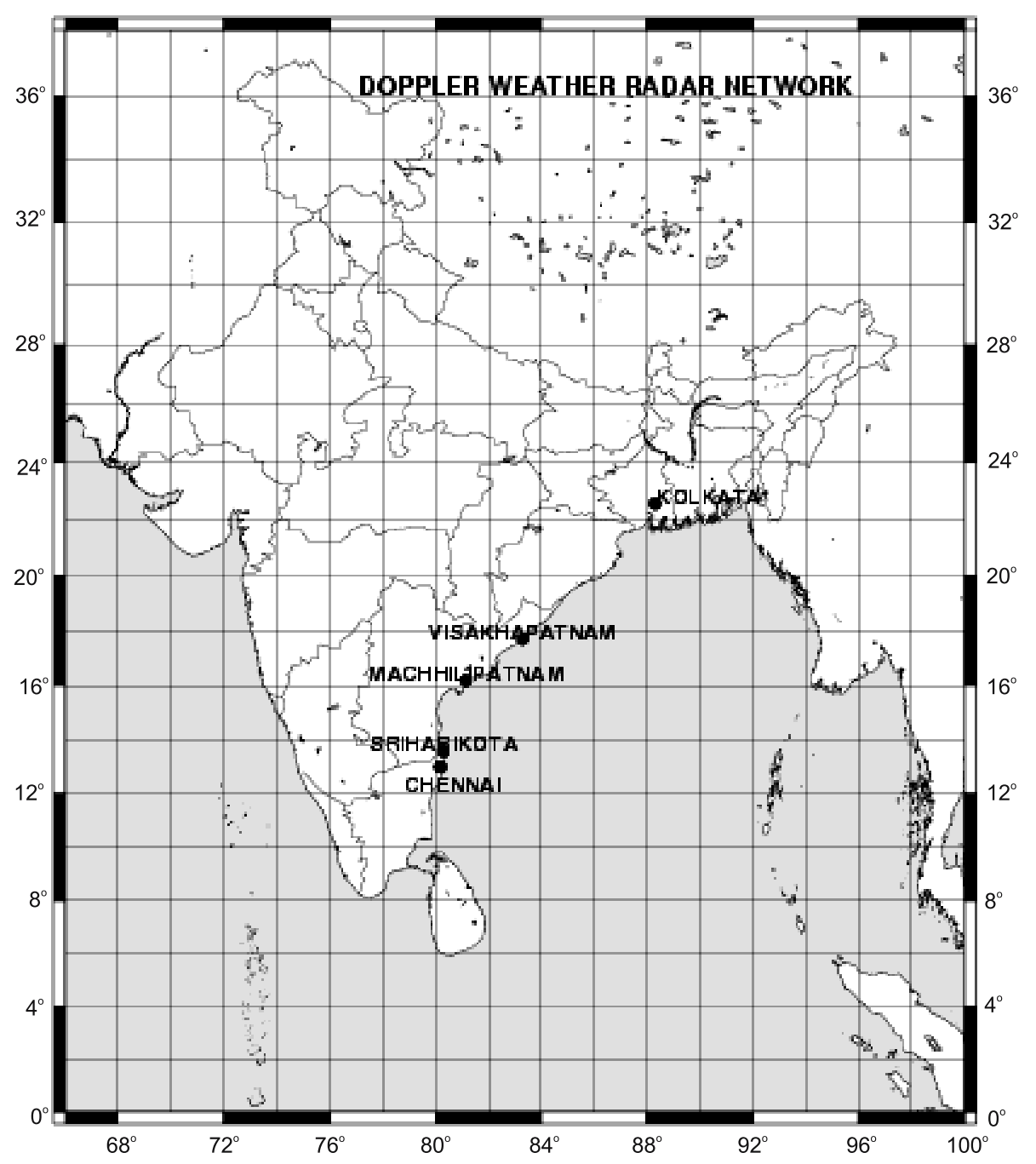

Figure 1. The current S-Band Doppler Weather Radar network in India.

Pradhan 2006; Suresh 2007, etc.). Realizing the importance of DWR observations in mesoscale and microscale weather analysis and forecasting, Srivastava et al (2010) carried out a study on the assimilation of DWR radial wind and reflectivity into ARPS model for high impact weather events over the Indian region.

This paper demonstrates the processing of DWR observations of Chennai $\left(13.01^{\circ} \mathrm{N}, 80.268^{\circ} \mathrm{E}\right)$ from the use of radar algorithms of the Warning Decision Support System - Integrated Information (II generation) (WDSS-II) application software (Lakshmanan et al 2007) for the nowcasting of mesoscale aspects of the Bay of Bengal cyclone Ogni of October 2006. The DWR at Machilipatnam $\left(16.12^{\circ} \mathrm{N}, 81.08^{\circ} \mathrm{E}\right)$ too tracked the storm during the final stages. However, DWR data of this station was not available at sufficiently high temporal and spatial resolution as required for the analysis. The present study analyses various scan strategies, to apply WDSS-II algorithms for quality control of DWR observations and generation of various nowcast products. The study provides an in-depth view of the structure of a tropical cyclone in this region of the world and makes a case for an improved disaster warning system for severe weather phenomena in India utilizing radar observations. Finally, we discuss various operational issues related to data collection strategies, networking, realtime analysis, shortcomings and operational constraints.

\section{Bay of Bengal tropical cyclone Ogni of October 2006}

In October 2006, the Andhra coast (eastern peninsular coast) of India was hit by a tropical cyclone named Ogni. The size of the cyclone was so small (diameter $100 \mathrm{~km}$ ) that operational synoptic weather charts and numerical model outputs failed to capture the system till it was well organized into a cyclonic storm. 


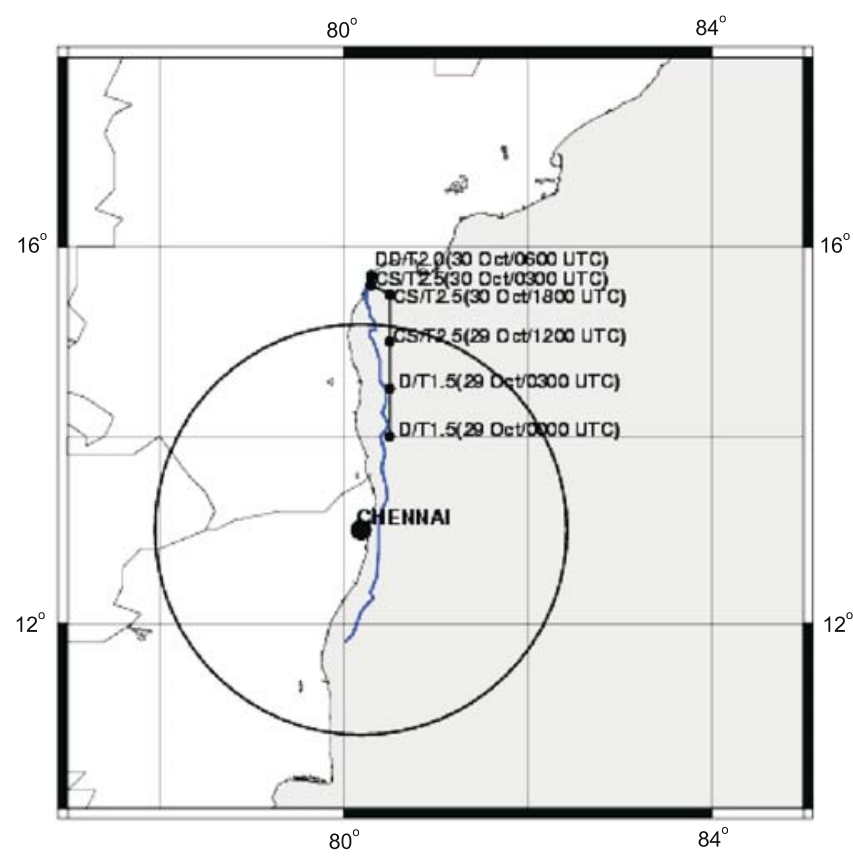

Figure 2. The track of the cyclonic storm from the depression stage to the point of landfall according to IMD (2007) (in black) and Chennai Radar Station (in blue). The legend in the figure indicates D (depression stage), DD (deep depression stage) and CS (cyclonic storm stage). The range circle indicates approximately $250 \mathrm{~km}$.

Cyclone Ogni was first seen as a low pressure area over west-central Bay of Bengal off the Tamil Nadu coast near Nagapattinam (latitude about $11^{\circ} \mathrm{N}$ ) during the morning of 28 October 2006. Since the storm track was mostly parallel to the coast, it was well within the range of the DWR at Chennai to track the evolution of the system from the depression stage to cyclonic intensity. Figure 2 illustrates the track of the cyclonic storm from the depression stage to the point of landfall (in black) according to the cyclone report of IMD (RSMC 2007). The blue line in figure 2, illustrates the track of the cyclone Ogni as measured by the DWR station at Chennai. This track is observed to be slightly different from the track in the cyclone report, which is prepared after taking into account all sources of observation, including radar data from all DWR stations. To avoid confusion, subsequent sections will refer to the track and intensity estimates of the cyclone as reported by IMD (RSMC 2007).

According to the cyclone report prepared by IMD (RSMC 2007), the low pressure system intensified into a depression and lay centered near lat. $14.0^{\circ} \mathrm{N} /$ long. $80.5^{\circ} \mathrm{E}$ during the morning of 29 October 2006. While moving slowly in a northerly direction, it intensified into a deep depression and lay centered near $15.0^{\circ} \mathrm{N} / 80.5^{\circ} \mathrm{E}$ during the afternoon of the same day. The system further intensified into a cyclonic storm and moved slightly northward. Till the morning of 30 October, the movement of the system was very slow. Thereafter, it moved north-westward and crossed the Indian coast north of Chennai at Bapatla, as a deep depression around noon of October 30, 2006. Observationally, it was a small core system and it attained cyclonic intensity for a few hours only. As a result of this system, there was heavy to very heavy rainfall over north Tamil Nadu, Andhra Pradesh and south Orissa coast $(55 \mathrm{~cm}$ over Gudivada $\left(16.43^{\circ} \mathrm{N}, 80.98^{\circ} \mathrm{E}\right)$ and $34 \mathrm{~cm}$ over Machilipatnam on 31 October), during this period.

The cyclone was observed to have a relatively narrow core in which the maximum wind sharply reduced to nominal values beyond about 40 to $50 \mathrm{~km}$ from the centre. The wind speed over the eye-wall region at sea level was quite strong although the aerial extent of high winds is relatively less. The half of the system closer to the coast had lesser velocity probably due to frictional loading. Maximum reliable record of wind speed is about $38 \mathrm{mps}$ at levels between 3 and $4 \mathrm{~km}$ above mean sea level (29 October at 0618 UTC to 29 October at 1218 UTC). Local print media reported incidents of fishermen (all along north Tamil Nadu and Andhra coast) experiencing heavy winds, with some of them missing during the period 29 October to 2 November 2006.

\section{Methodology and analysis of results}

The analysis was carried out offline on 72 hours of Doppler moment (equivalent to NEXRAD Level-II) data. The data was subsected to form a synthetic Volume Coverage Pattern (VCP). The data were then analyzed using the WDSS-II algorithms and display programs, developed jointly by the National Severe Storms Laboratory and the University of Oklahoma. WDSS-II includes implementation of several severe storm analysis applications that are operational on the NEXRAD Open Radar Products Generator (ORPG) and next-generation algorithms. In this paper, we will describe the analyses that are carried out on the Chennai DWR data using algorithms which are currently operational at NSSL, USA.

\subsection{Data setup}

The DWR, whose data were used in this analysis, has a beamwidth of $1^{\circ}$ and provides 360 "beams" or radials of information per elevation angle. The volume covered by one complete $360^{\circ}$ rotation at one elevation angle is called an elevation scan. The area covered by the radar beam as the antenna rotates through several elevation scans is known 
Table 1. Scan strategy of DWR Chennai for cyclone Ogni and the creation of a synthetic VCP from the volume scan used for analysis.

\begin{tabular}{lccccc}
\hline $\begin{array}{l}\text { Elevation/ } \\
\text { minutes }\end{array}$ & 0,30 & 3,33 & 15,45 & 18,48 & Synthetic \\
\hline $0.2^{\circ}$ & yes & yes & yes & yes & yes \\
$1.0^{\circ}$ & yes & yes & yes & yes & yes \\
$2.0^{\circ}$ & yes & yes & yes & yes & yes \\
$3.0^{\circ}$ & yes & yes & yes & yes & yes \\
$4.5^{\circ}$ & yes & yes & yes & yes & yes \\
$6.0^{\circ}$ & yes & yes & yes & yes & yes \\
$7.5^{\circ}$ & yes & yes & yes & yes & yes \\
$9.0^{\circ}$ & yes & yes & yes & yes & yes \\
$11.0^{\circ}$ & & yes & & yes & no \\
$13.0^{\circ}$ & & yes & & yes & no \\
$15.5^{\circ}$ & & yes & & yes & no \\
$18.0^{\circ}$ & & yes & & yes & no \\
$21.0^{\circ}$ & & yes & & & no \\
Bins/ray & 416 & 416 & 416 & 250 \\
Gate width (km) & 0.6 & 0.6 & 0.6 & 0.6 & 1.0 \\
Clutter filter & 1 & 1 & 1 & 1 & 1 \\
Long pulse (PRF) & 600 & 600 & 600 & 300 & 0 \\
Short pulse (PRF) & 0 & 400 & 0 & 0 & \\
\hline
\end{tabular}

as a volume scan. The DWR at Chennai follows a series of different VCPs within a thirty-minute interval. The scans and their related parameters are listed in table 1. Doppler filter numbers represent the notch-width of the filter, which is a function of both transmitter (Tx) frequency (fc) and the PRF:

- Doppler Filter 1 has a notch width of $0.2 \mathrm{~m} / \mathrm{s}$ for $\mathrm{fc}=2875 \mathrm{MHz}, \mathrm{PRF}=1200 \mathrm{~Hz}$.

- Doppler Filter 1 has a notch width of $0.04 \mathrm{~m} / \mathrm{s}$ for $\mathrm{fc}=2875 \mathrm{MHz}, \mathrm{PRF}=250 \mathrm{~Hz}$.

Utilization of the radar data in any automated analysis scheme such as WDSS-II requires a predictable scan strategy of the data and at relatively short intervals $(<12 \mathrm{~min})$. Algorithms based on temporal aspects of pattern recognition will provide improved forecasts only when the data is of reasonably high quality (quality controlled), frequently updated (within 10-12 min) in a predictable manner and the scan strategy is consistent. This is especially true for tropical convective storms in which cells have rapidly changing characteristics. Hence, the data flow (e.g., VCP update rate) must also be sufficiently high to capture the evolution of the phenomena of interest. However, as is clear from table 1 , some scans (e.g., the $11^{\circ}$ scan and above) by the Chennai DWR are collected only once every 15 minutes. Therefore, these elevations are not of much use for incorporation into any automated analysis algorithm.
In view of the above problems, a synthetic VCP 301 has been subsected out for all the data available. This virtual volume has data at the same elevation angles as the 00 and 15-minute scans. However, in addition to the above two VCPs, we also extract the corresponding information from the 03 and 18-minute scans. The bins per ray and the gate-width for the synthetic VCP 301 are retained at 250 and 1.0, respectively. The data at $0.6 \mathrm{~km}$ bin slots were re-sampled to $1 \mathrm{~km}$ bins using a nearest neighbour interpolation scheme. Hence the final VCP 301, as shown in the above table is available at $00,03,15,18$ minutes in every half an hour. The Pulse Repetition Frequency (PRF) for a particular tilt is used to compute the Nyquist velocity for the velocity data of the corresponding scan.

Figure 3 displays the algorithms applied on the Indian radar data. The boxes indicate the WDSS-II algorithms. The grey boxes indicate the WSR-88D legacy algorithms that have been transported to the WDSS-II platform and implemented on the radar data. Figures for the underlined products are displayed in the corresponding sections.

\subsection{Dealiasing of velocity data}

An operational challenge in using Doppler radar velocity field is that velocity measurements are often aliased (folded). Aliasing occurs whenever the pulse repetition frequency (PRF) of the radar is lower than twice the Doppler frequency shift to be 


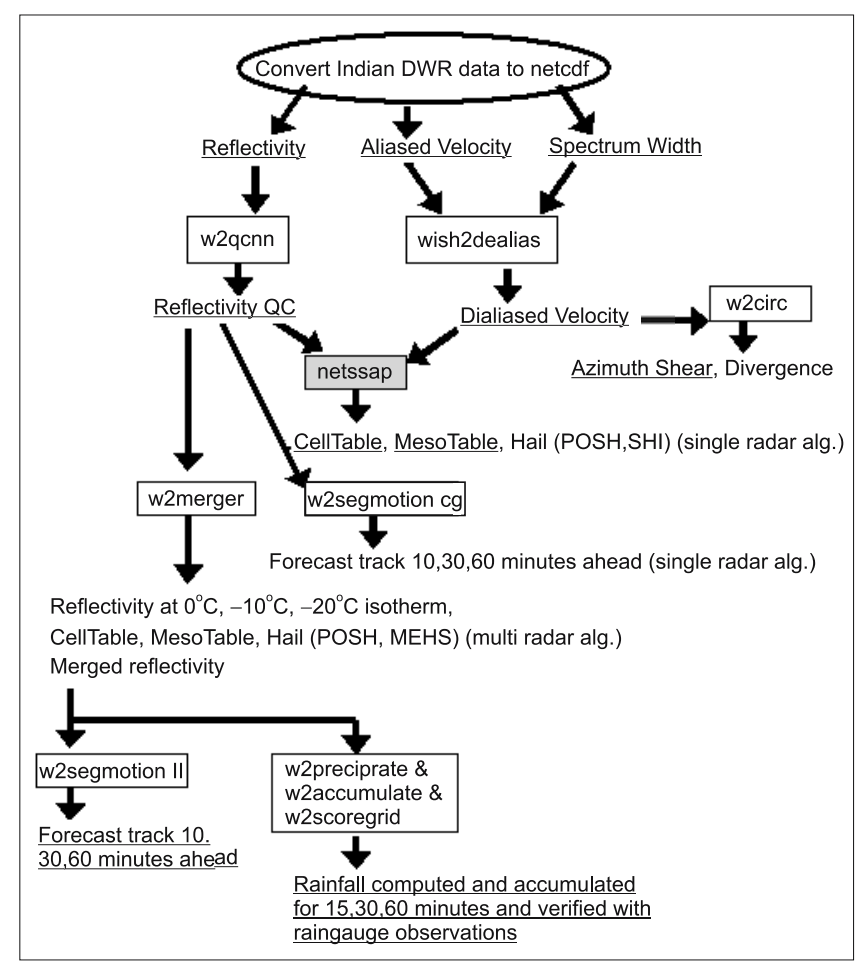

Figure 3. Algorithms applied on the Indian radar data. The boxes indicate the WDSS-II algorithms. The grey box (SSAP) indicates the WSR-88D legacy algorithms that have been transported to the WDSS-II platform and implemented on the radar data. Figures for the underlined products are displayed in the corresponding sections.

measured. Velocity aliases can usually be identified based on discontinuity in the measured Doppler velocity field.

Of the eight sets of scan in every hour, at HH:00, $03,15,18,30,33,45,48$ only two (HH:03,33) had employed dual PRF (600/400, 3:2) technique. Before combining these datasets for generating synthetic VCP 301, dealiasing is done at signal processor level (Dual PRF technique). Thus the level II data ingested into the WDSS-II software corresponding to HH:03 and HH:33 minutes are with less aliasing due to Dual PRF 600/400, HH:18, HH:48 minutes are with maximum aliasing as PRF is 300 and HH:00, 30, 15, 45 with partial aliasing as PRF is $600 \mathrm{~Hz}$. After the data are composed into a synthetic VCP, there is an attempt to dealias the velocity data at data level to complement the previous dealiasing procedure.

The current dealiasing technique at the data level for NEXRAD radars is the Local Environmental Dealiasing (LED) scheme of Eilts and Smith (1990). A climatological average profile is used as an independent estimate of the true velocity to initially start the procedure to look for two-dimensional spatial and temporal continuity. While this procedure is computationally quite efficient, this technique still has difficulties for cases with strong shear and small Nyquist velocities and in cases of large data voids. Figure 4(a) presents the original aliased velocity field for the tropical cyclone at 1648 UTC of 28 October 2006 and figure 4(b) displays the velocity field for the same time, dealiased by the LED technique. The figure displays a highly aliased velocity field in the neighbourhood of the future centre of the cyclonic storm. This indicates that there are large sectors of the velocity field that have not been dealiased properly by this technique, leading to a misrepresentation of the velocity field.

In this respect, a newer, 2D (radial and azimuth) multiple pass technique was developed by Zhang and Wang (2006) which eliminates the dependence on external data sources. This technique is also based on continuities in velocity field along radial and azimuth directions. This algorithm was found to successfully dealias most of the data in the present case. Figure 4(c) illustrates the velocity field of the same time, dealiased by the above newer technique. The severe shear of the velocity field has been properly dealiased by the above technique. Though this technique too sometimes gives errors, especially in the case of low reflectivity, and when echoes move distances at integral multiples of wavelength causing $2 \pi$ multiples of phase shifts, it is generally able to dealias the velocity corresponding to higher reflectivity echoes, which are of greater concern.

\subsection{Quality control of reflectivity data}

Weather radar data are subject to many contaminants, mainly due to non-precipitating targets and due to anomalous propagation or ground clutter. By removing the ground clutter contamination, estimates of rainfall from the radar data can be improved (Kessinger et al 2003) and false alarms are prevented from the operational mesocyclone detection algorithm (Stumpf et al 1995).

In addition to the multiple VCPs, error in the estimation of the evolution of a weather phenomenon may arise due to clutter in the radar data. The clutter in an image may arise from two main sources:

\section{- Ground clutter contamination and}

- Anomalous propagation.

The high value of reflectivity $(z)$ close to the radar almost throughout the day may be due to improper clutter removal by the radar manufacturer's software. Appropriate clutter filter techniques have to be applied (as has been done in the present case) to remove this type of clutter from the reflectivity scan images.

Other than the ground clutter as discussed above, the data have to be quality Controlled to 
(a)

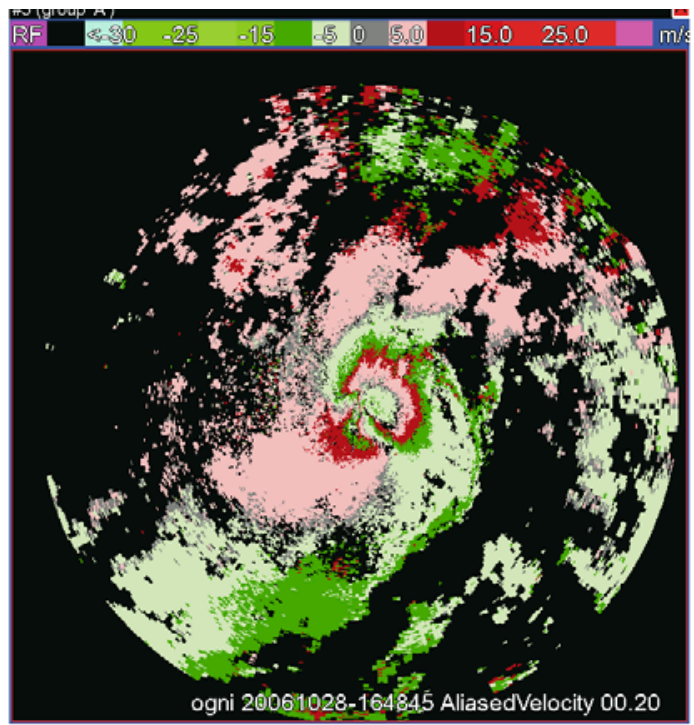

(b)

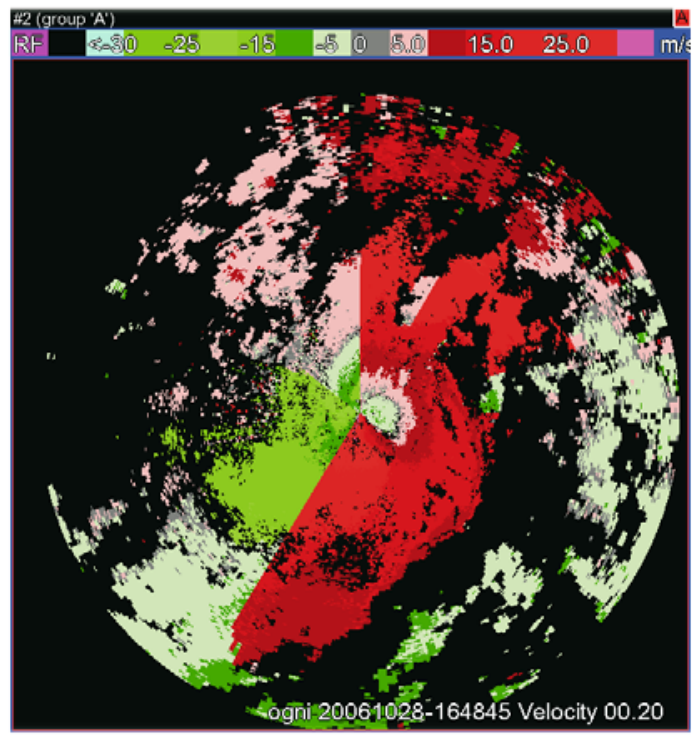

(c)

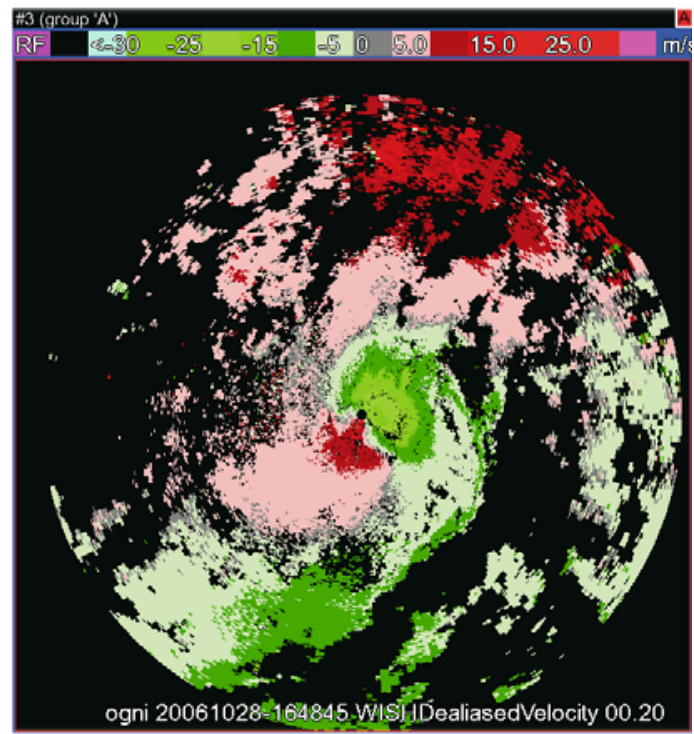

Figure 4. (a) The original aliased velocity field for the tropical cyclone Ogni at 1648 UTC of 28 October 2006. (b) The velocity field for the same time, dealiased by LED technique. (c) The dealiased velocity field of the same time, dealiased by the newer technique of Zhang and Wang (2006). remove other non-weather echoes. The most significant error echoes are due to anomalous propagation of the radar beams at the lowest elevations, close to the ground. These echoes are produced during super-refractive conditions by ground clutter when the beam bends more than normal close to the ground. These echoes are generally radially oriented and there is transient clutter contamination of scans. These echoes show wide reflectivity variations over large areas and lack uniformity or smooth reflectivity gradients. For example, the reflectivity field in figure 5(a) at 0430 UTC of 28 October 2006, where the anomalous propagation errors are clearly visible in the northeast and southern sectors of the image.

These data can be quality controlled using just the radar moments. Lakshmanan et al (2003a) have developed a scheme that uses texture features as inputs to a neural network that can distinguish between precipitating and non-precipitating radar echoes. The neural network was trained on NEXRAD data consisting of 14 volume scans of data using a million point dataset. The same scheme was used for the Indian radar data and was found capable of distinguishing most precipitation echoes from surrounding clutter. When these algorithms were applied on Indian Doppler weather radar data, there were some specific situations where the texture features used as inputs to the neural network did not possess sufficient discrimination power. These situations include the presence of large, spatially smooth, clear-air returns. As may be observed from figure 5(b), the neural network is able to remove most of the anomalous propagation errors. In addition, it also removes some of the spatially smooth, low reflectivity, clear air returns. The algorithm makes its mistakes on lower reflectivity values but gets higher reflectivity values (which are of concern during severe weather) correct more often.

\subsection{Estimation of rotation and divergence}

The azimuthal shear, is the derivative of the wind velocity in azimuth direction. In the present case, an algorithm has been applied that uses a two-dimensional, Local Linear Least Squares Derivative (LLSD) method to minimize the large variances in rotational and divergent shear calculations (Smith and Elmore 2004). The azimuthal shear and divergence signatures are found particularly useful in detecting developing cloud clusters, in areas of mesoscale cumulogenesis. In the present case figure 7 displays the vertical structure of the azimuthal shear in the region of a mesocyclone. The sharp change in the azimuthal shear in the lowest $2 \mathrm{~km}$ height is corroborated by the reflectivity maximum at the corresponding height. 

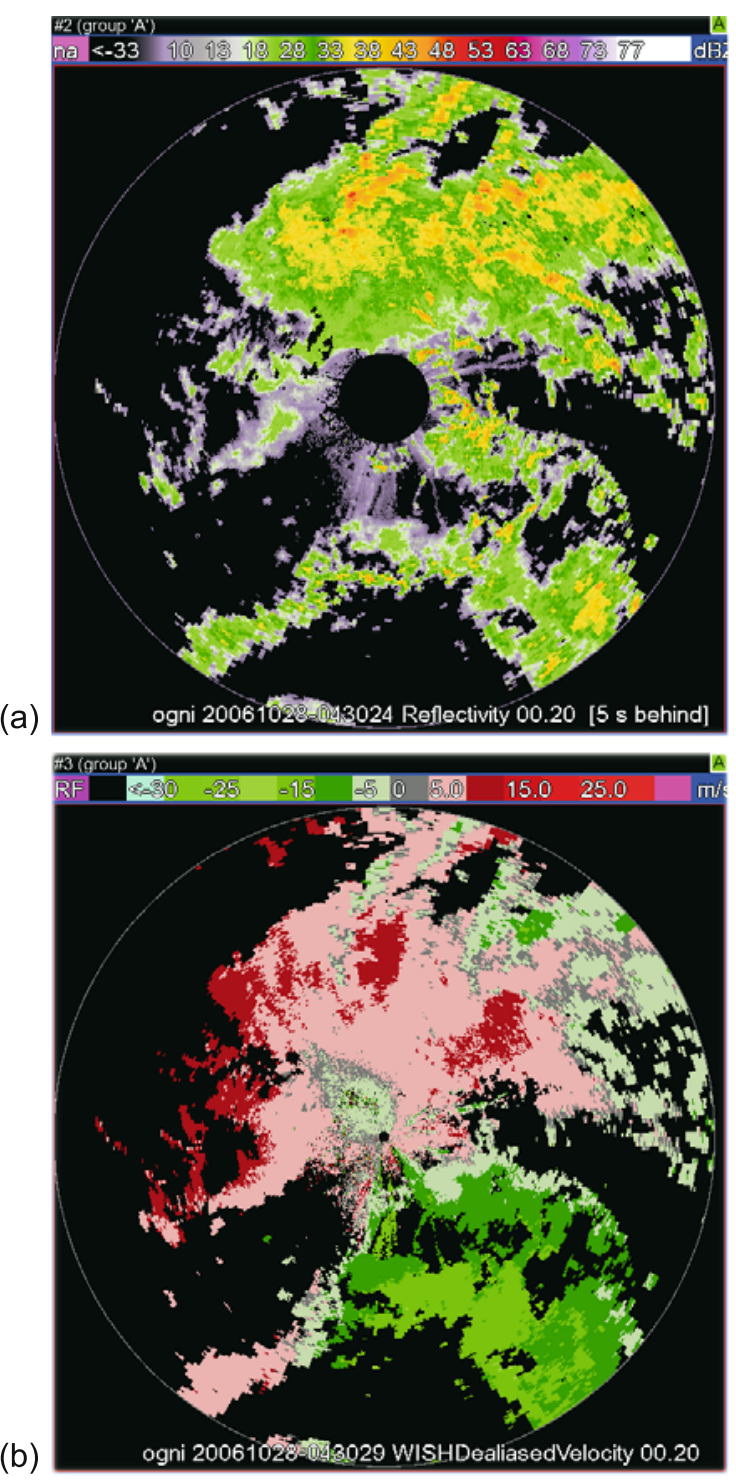

(b)

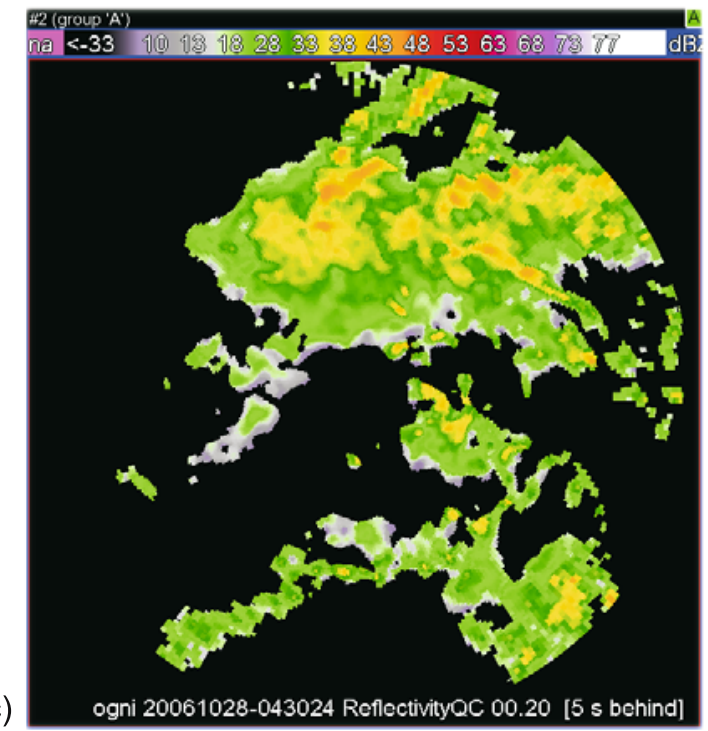

Figure 5. (a) Original reflectivity field at 0430 UTC of 28 October 2006 at 00.20 degree elevation, (b) the corresponding dealiased velocity field, and (c) the reflectivity field for the same time after the quality control algorithm has been applied.

\subsection{Storm cell tracking}

The Storm Cell Identification and Tracking (SCIT) algorithm (Johnson et al 1998) is a single radar algorithm. It processes volumetric reflectivity information from radar base data on a radial-byradial basis. The algorithm repeats the process of centroid identification using seven different reflectivity thresholds (reflectivity: 60, 55, 50, 45, 40, 35, and $30 \mathrm{dBZ}$ ). The algorithm uses these thresholds of reflectivity, length of segments, area of components (as well as other thresholds) and presence in at least two consecutive elevation angles to detect a storm. The centroids are then used as a proxy for the storms (Johnson et al 1998) and tracked either on the basis of proximity to expected position or through a linear programming approach.

Prior to the organization of the cloud mass into a tropical cyclone, numerous small independent cloud clusters formed, precipitated and dissipated in the neighbourhood of the future storm center off the coast of Chennai. Figure 6(a) displays the reflectivity scan at the lowest elevation at a particular instant of time at 1233 UTC of 28 October, 2006. The SCIT cell tracker detects numerous cells at this instant of time. Position and past track (in pink) for seven cells is displayed in this figure. The parameters of all such cells identified in the current scan are displayed in tabular form. These include POSH (Probability of Severe Hail), corresponding hail size, Vertically Integrated Liquid (VIL) in the cell, height of maximum reflectivity as well as current location and probable direction of motion and speed. These cells are tracked through successive scans and their parameters are modified according to the intensification or decay characteristics of the cell or until their shape changes so much that they are to be identified again with a new cell identity. While the cells in these small clusters are well identified and tracked by the above algorithm, once the main system organized itself, the cells in the bands surrounding the system were not so well identified or tracked by the above algorithm. Also, since no velocity data are processed by this algorithm, the forecast performance is more accurate for short term forecasts than long term forecasts.

With the development of communication networks and computer power, data from multiple sensors (mesoscale models, satellite, etc.) and multiple radars are available in near real time to forecasters and they have been the impetus to the development of a new generation of multi-sensor severe storm analysis algorithms that provide better analysis and more accurate forecast for severe weather. The Multi-Radar Severe Storm Analysis Program (MRSSAP) (Stumpf et al 2002) combines the twodimensional information from multiple radars and mosaics it into virtual volume scans (Lynn and 


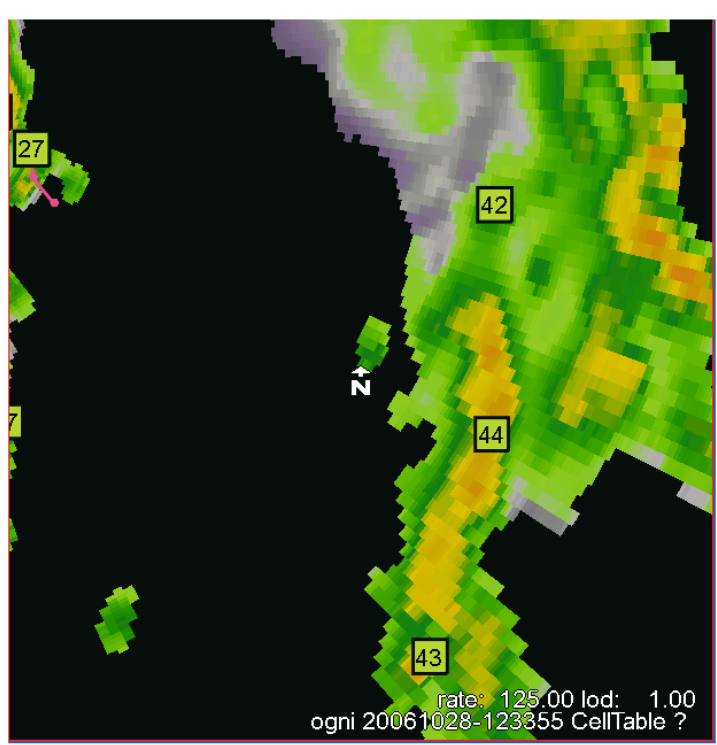

(a)

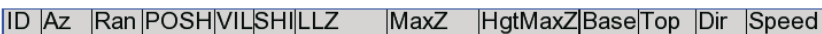

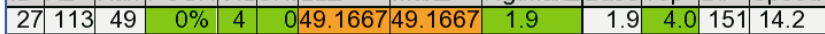

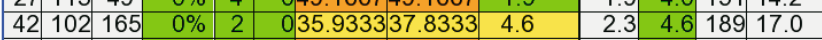
\begin{tabular}{|l|l|l|l|l|l|l|l|l|l|l|l|}
42 & 102 & 165 & $0 \%$ & 2 & 035.9333 & 37.8333 & 4.6 & 2.3 & 4.6 & 189 & 17.0 \\
\hline 43 & 135 & 206 & $0 \%$ & 9 & 146.9 & 46.9 & 3.5 & 3.5 & 6.3 & 177 missing \\
\hline
\end{tabular}

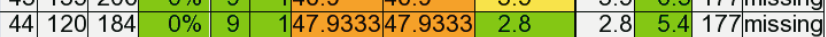

(b)

Figure 6. (a) Some of the cells and their corresponding tracks (in pink), detected by the single radar SSAP algorithm of Johnson et al (1998) at 1233 UTC of 28 October 2006. (b) Some of the characteristics include cell identity (ID), Azimuth (Az), Range (Ran), Probability of Severe Hail (POSH), Vertically Integrated Liquid (VIL), Severe Hail Index (SHI), Low Level Reflectivity (LLZ), Maximum Reflectivity (MaxZ), Height of Maximum Reflectivity (HgtMaxZ), Probability of Hail (POH), Base of cell (Base), Top of cell (Top), Probable direction of movement (Dir), Probable speed of movement (Speed).

Lakshmanan 2002), with the latest elevation scan of data replacing the one from a previous volume scan. This allows for a more complete 3D sampling of storms and mesocyclones/TVS (Tornado Vortex Signature) where vertical sampling resolution is degraded. Signatures are better sampled where adjacent radars are adding data to poorly sampled regions such as cones-of-silence.

As already mentioned, in the absence of radar data at the sufficiently high resolution from the Machilipatnam, it is not feasible to test the improvement in the nowcasting accuracy with the incorporation of multiple DWRs.

\subsection{Mesocyclone detection}

The current mesocyclone detection algorithm (MDA) (Stumpf et al 1998) follows an automated vortex detection technique to classify and diagnose a storm as a mesocyclone on the basis of $4 \mathrm{D}$ properties of the storm. It also includes multiple range dependent strength thresholds, a robust 2D feature identifier, an improved 3D vertical association technique and addition of time association and trends to vortex attributes. The MDA attempts to detect all storm scale vortices and then diagnose them to determine if they are significant.

Tropical cyclones may spawn mesocyclones either ahead of, during or after landfall. However, since the shear in a tropical environment is relatively weak (Barnes 2001), especially in association with formation and maintenance of tropical cyclones, the mesocyclones thus formed, rarely attain sufficient strength to produce tornadoes. In the present case, some mesocyclones were identified north of the main system in the initial phase of the formation of Ogni. These generally formed in the northwest, along the outer rainband of the main system close to the zero velocity line. While most of these mesocyclones decayed within 10-15 minutes of their formation, a few of them lasted for more than 20 minutes and permitted a more indepth analysis of the characteristics of mesocyclones. Figure 7(a) shows the location (close to the outer rainband of the developing cyclone system) and vertical structure of such a mesocyclone. The vertical structure of the reflectivity field in the neighbourhood of the mesocyclone is displayed in figure $7(\mathrm{~b})$ while the horizontal shear field is displayed in figure $7(\mathrm{c})$. The mesocyclone generally showed northward movement and the maximum intensity observed to be $40 \mathrm{dBZ}$ at $2 \mathrm{~km}$ height with a tilt to the west, on the landward side of the mesocyclone. The horizontal shear detected in this mesocyclone is comparable to those detected by Rao et al (2003) for the hurricane Floyd, and observed to change sharply with height (from 0.002 to $-0.002 \mathrm{~s}^{-1}$ over the lowest $2 \mathrm{~km}$ ).

\subsection{Composite}

Converting radar data to a lat./lon./height grid makes it easier to combine it with data from other sensors, particularly environmental data from a mesoscale model (e.g., $4.5 \mathrm{~km}$ WRF model output). The input of thermodynamic data is useful for deriving additional information from the radar data, e.g., values of reflectivity at constant temperature levels (e.g., at the melting level of $0^{\circ} \mathrm{C}$ ) and temperature layers, the height of constant reflectivity values above certain temperature levels (e.g., height of $50 \mathrm{dBZ}$ level above the $0^{\circ} \mathrm{C}$ level), and the various hail diagnosis parameters and improved storm nowcasting.

NSSL has developed the capability to merge multiple-radar data into a four dimensional (4D) mosaic of grids (Zhang et al 2004; Lakshmanan et al 2007). These grids are specified in latitude/ longitude/height/time coordinate systems. Values in grid cells sensed by more than one radar are 


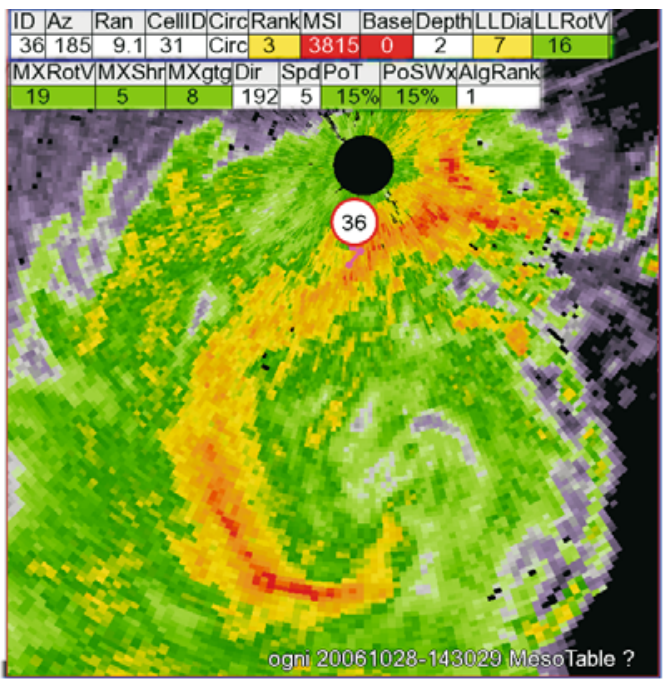

(a)

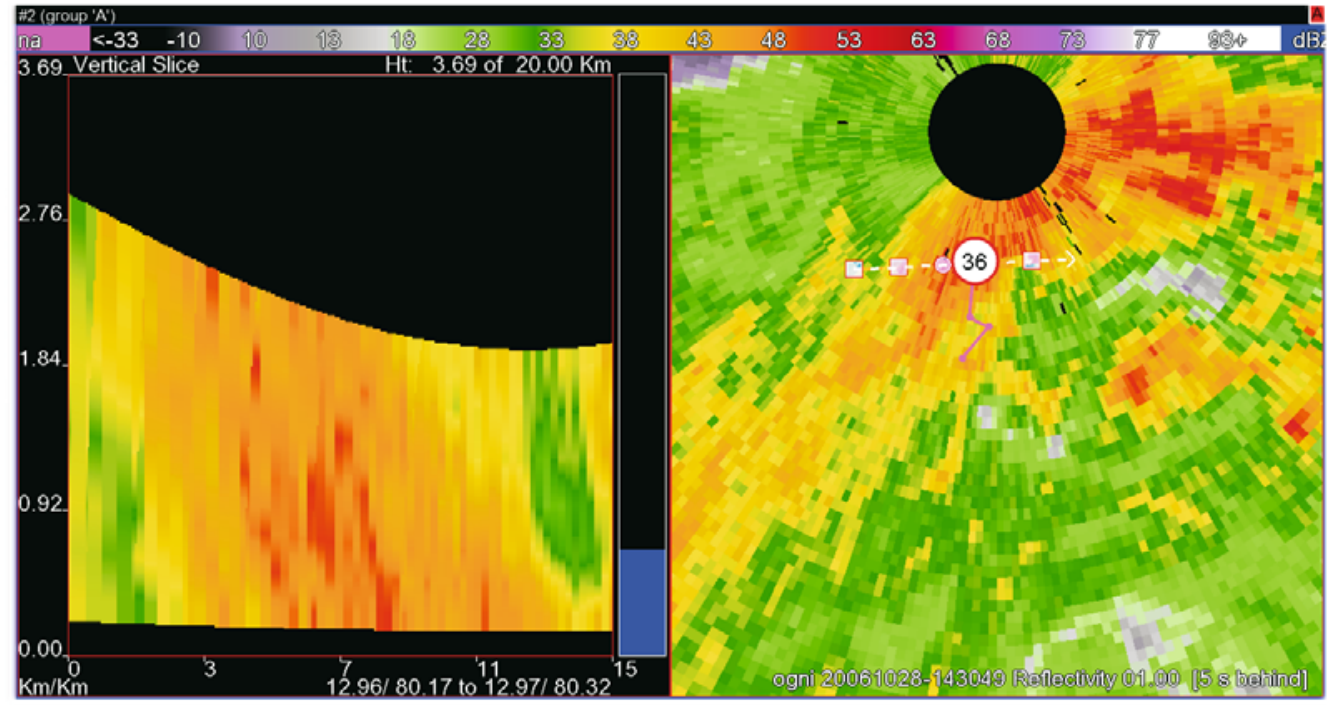

(b)

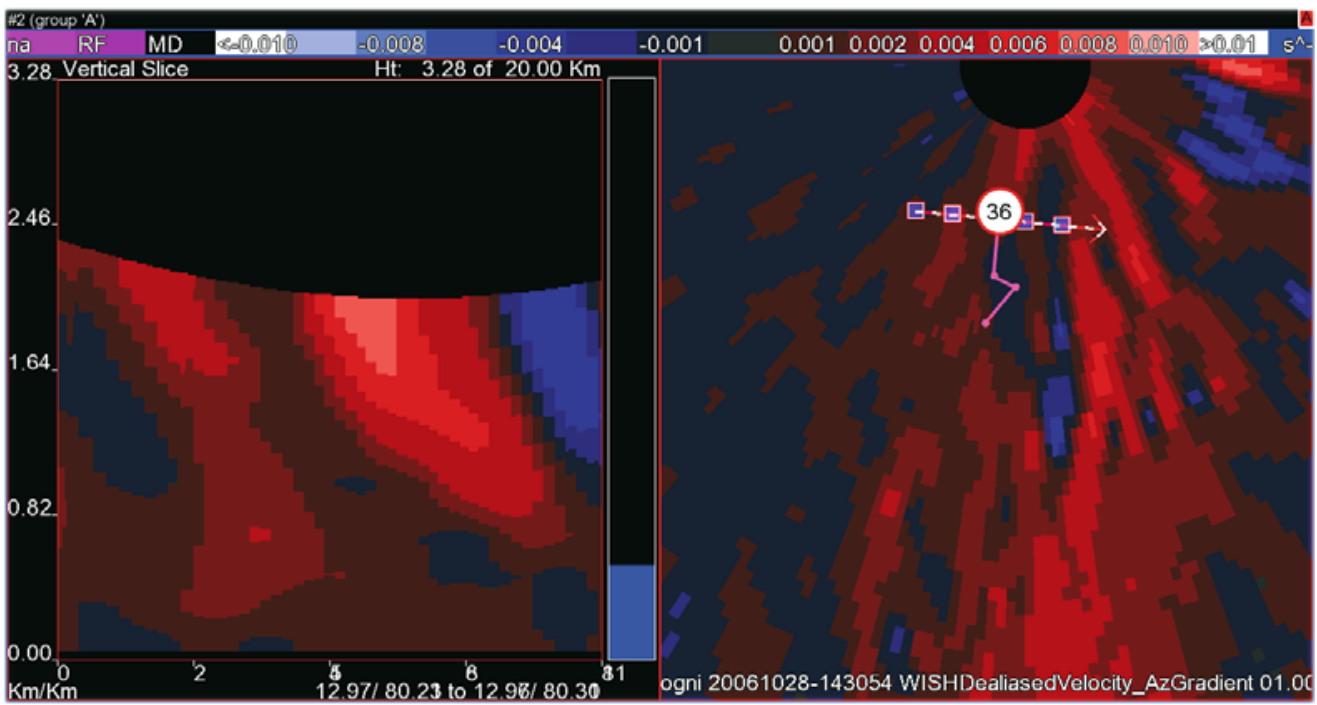

(c)

Figure 7. (a) Snapshot showing the location of a mesocyclone at 1430 UTC of 28 October, close to the outer rainband of the developing cyclone system. (b) The reflectivity structure along a vertical section. (c) The vertical structure of the horizontal shear field in the neighbourhood of the mesocyclone is shown for the same time. 


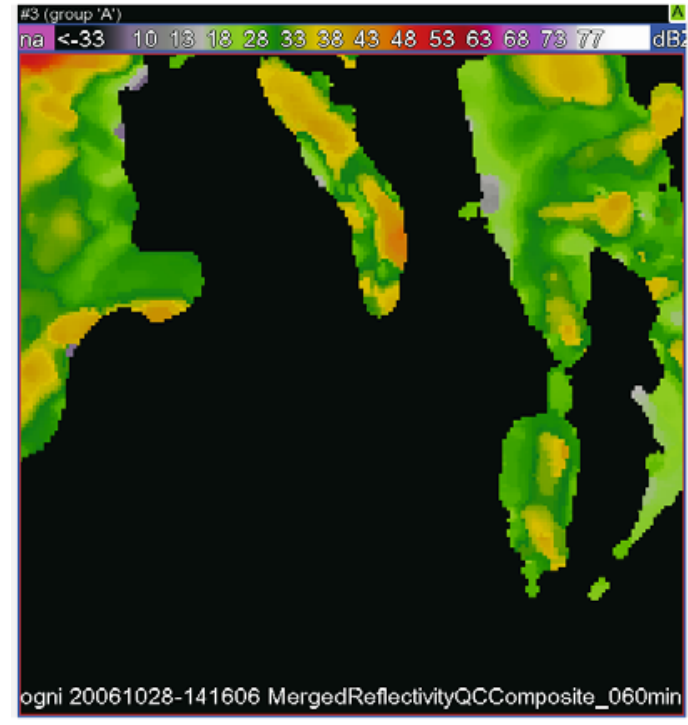

(a)

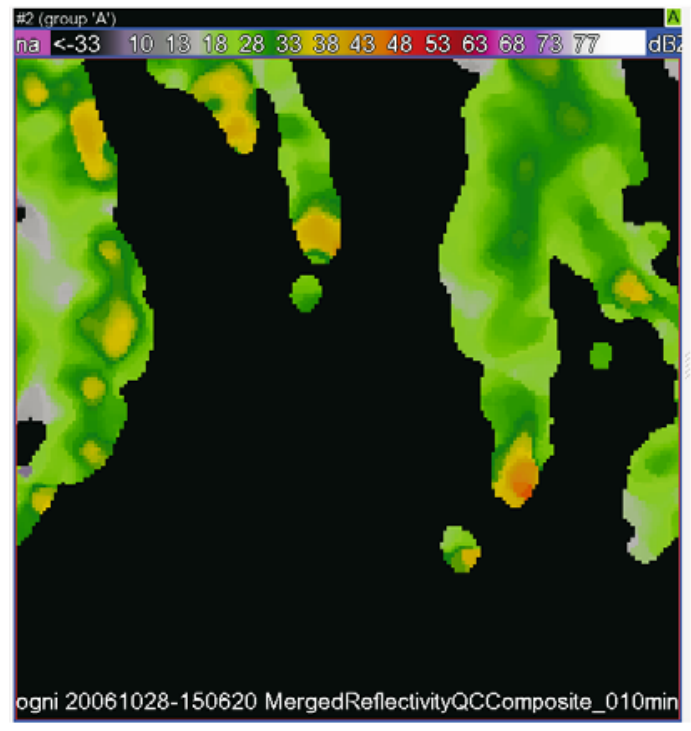

(c)

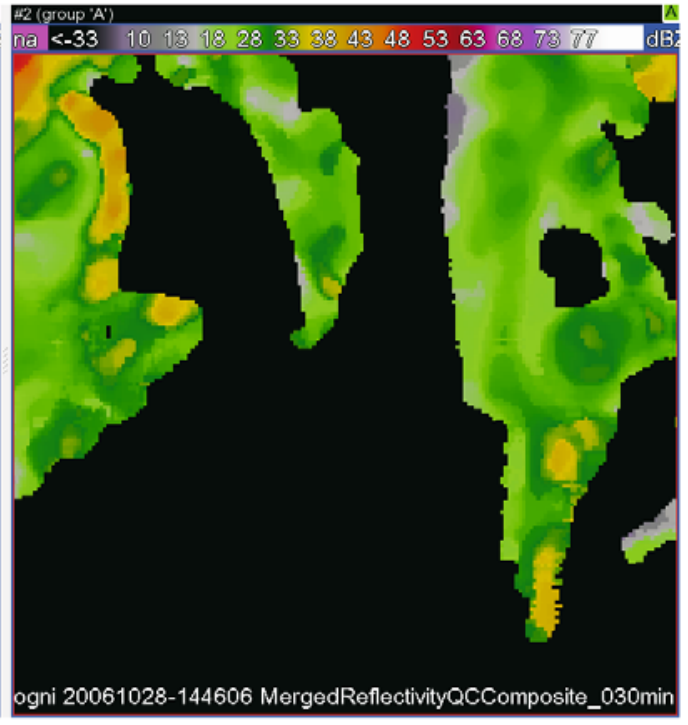

(b)

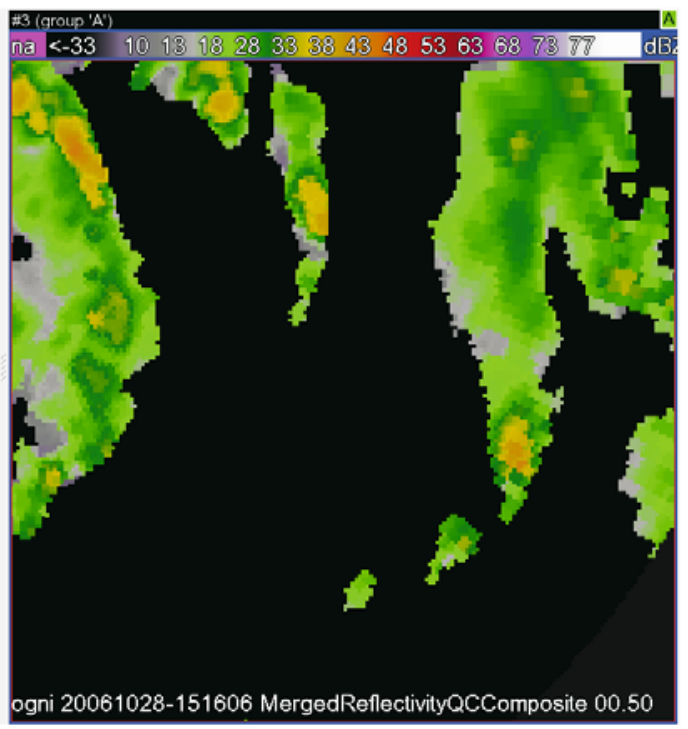

(d)

Figure 8. Radar reflectivity just before the system attained cyclonic storm intensity. While (a) displays the storm forecast 60 minutes ahead, (b) displays the storm forecast 30 minutes ahead for the same time, (c) displays the storm forecast 10 minutes ahead for the same time, while (d) displays actual storm structure at 1516 UTC of 28 October for which time all the above forecasts have been made.

combined using a time and an inverse distance weighting scheme. As already mentioned, the radar data collected from the Machilipatnam radar was at too low a temporal resolution to be combined with the data from the Chennai radar. However, the input to the rainfall algorithm is in the form of gridded data. So gridded maps of the reflectivity field are constructed with Chennai radar data alone, with spatial resolution $(1 \mathrm{~km}$ Cartesian grids) and updated every 5 minutes temporally.

\subsection{Forecast of echo growth and movement}

The centroid-based identification and tracking of storms as discussed above in section 3.5 can cause a number of tracking instabilities, especially with more organized systems. A newer, more sophisticated technique that uses a statistical clustering technique has been developed at NSSL to segregate and track multiple scales of reflectivity features to forecast the motion, growth, and decay of two dimensional storm fields (Lakshmanan et al 2003b). The motion estimation application begins with a statistical K-means clustering technique that can segregate multiple scales of reflectivity features in a hierarchical manner (larger clusters contain smaller clusters, and so on) and is done at three scales ranging from the tracking of individual cells to the tracking of large scale systems such as cyclones, which is more useful in 
this case. These clusters are tracked independently with greater stability than the centroid-based algorithms. Time histories of tracked cluster can then be diagnosed for trend information. An additional benefit of the technique is the ability to incorporate mesoscale model wind fields. This provides a more accurate estimation of the storm movement. The product also contains a storm growth and decay component.

Figure 8 is a snapshot of the system, during its initial stage as a low level circulation. While figure 8(a) displays the storm forecast sixty minutes ahead, for 1516 UTC of 28 October based on the data at 1416 UTC, figure 8(b) displays the storm forecast 30 minutes ahead for 1516 UTC based on the data at 1446 UTC, figure 8(c) displays the storm position forecast 10 minutes ahead for 1516 UTC based on the data at 1506 UTC, while figure $8(\mathrm{~d})$ displays the actual cell positions at 1516 UTC of 28 October.

The forecasts have all been taken for the same time to illustrate the variation in the accuracy of the forecast with different lead times. As may be observed, the algorithm accuracy decreases with the time length of the forecast. In this respect too, a model background wind field of a sufficiently high resolution, will contribute significantly to giving better forecast of the track and organization of the cells. The time taken to issue a nowcast (regardless of the length of the nowcast) is of the order of $10-20$ seconds. So, it is operationally feasible to issue nowcasts in realtime.

\subsection{Rainfall}

The quality controlled mosaic data from multiple radars (in this case, a single radar) is used to estimate the precipitation. This is essentially the NEXRAD precipitation algorithm with a sophisticated quality control technique and better convective/stratiform classification (Lakshmanan et al 2007 ). From the 3D grid, a 2D grid of reflectivity is estimated. In the $2 \mathrm{D}$ grid, the reflectivity at every point is given by the reflected power closest to the ground in the 3D grid. To prevent bright band issues, the reflectivity data uses the lowest level reflectivity below the $0^{\circ} \mathrm{C}$ height. Precipitation rates are estimated in WDSS-II using a Marshall-Palmer $z-R$ relationship (Marshall and Palmer 1948): $z=a R^{b}$, where $R$ is the rain-rate in $\mathrm{mm} / \mathrm{h}, z$ is the radar reflectivity in $\mathrm{mm}^{6} \mathrm{~m}^{-3}$ and $a$ and $b$ are constants. The default settings recommended by Fulton et al (1998) for mid-latitude conditions were used: $a=200$ and $b=1.6$ in areas of stratiform rainfall and $a=300$ and $b=1.4$ in areas of convective activity. The presence or absence of hail as determined by the Severe Hail Index (SHI) is used to discriminate between stratiform and convective precipitation. By means of groundtruth studies, precipitation observed by gauges can be related to the corresponding radar estimate of rainfall at a point for a more rigorous calibration. However, there are several potential or real sources of error in such comparisons: shadowing, anomalous propagation and ground clutter in the radar echo and uncertainty due to differences in the location of the sampled radar volume $v s$. the corresponding ground location, are some of the radar problems of precipitation measurement. Gauge observations are also subject to representative errors related to their siting and location, which means that the true relationship between radar-sampled precipitation and gauge precipitation observations will vary from station to station. Despite all these potential sources of error, data from two self-recording rain gauges located at Vellore $(110 \mathrm{~km})$ and Madras $(16 \mathrm{~km})$ were chosen to objectively validate the radar estimate of rainfall (figure 9a) obtained at 15-minute intervals. The station locations are shown in figure 9(b). Since the data for only the cyclone period was too small a sample size to produce significant validation results, we validated the rainfall algorithm with the rainfall data for a whole month, October 2005. This was a wet month and a significant sample volume was available for validation.

The radar rainfall estimates accumulated for 15 minutes, 30 minutes (figures not shown) and 60 minutes were checked for the accuracy and bias in the estimate. Mean error, which is the difference between the radar observation and the rain gauge observation, has been computed for each rainfall accumulation interval. It may be seen from figure 9 (c) for 60-minute accumulations, that at most times, the rain rate by the radar was close to the values measured by the rain gauge. However, there is a greater negative bias in the results indicating the frequency of underestimation by the radar. This error increases with the period of accumulation, i.e., it is minimum for 15-minute accumulation, and increases as the period of accumulation increases. The Mean Square Error was used to measure the accuracy of the radar rainfall estimate (figure 9d). This too demonstrates that the algorithm is relatively accurate for short period accumulations, but error increases with the period of accumulation. However, it may be noted that the values of $a$ and $b$ in the $z-R$ relation have been derived for mid-latitude conditions and need further optimization for tropical conditions before this algorithm can be used operationally.

\section{Discussion and future outlook}

In the near future India Meteorological Department is going to install a good network of DWR. 


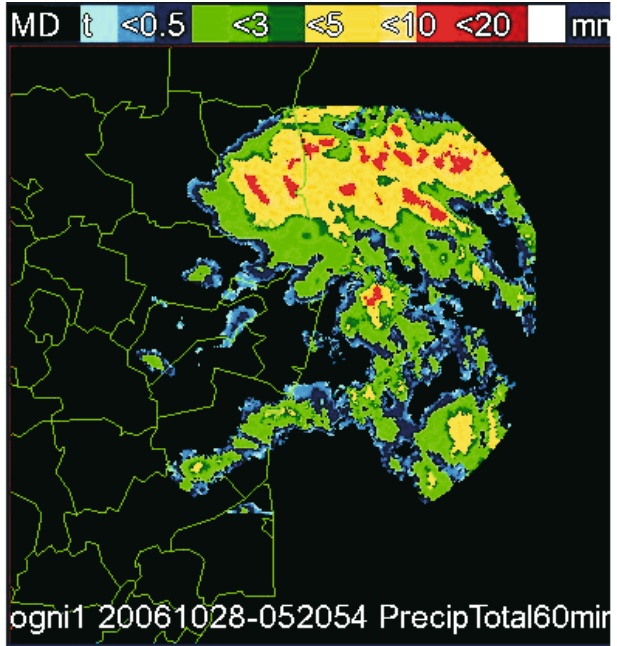

(a)

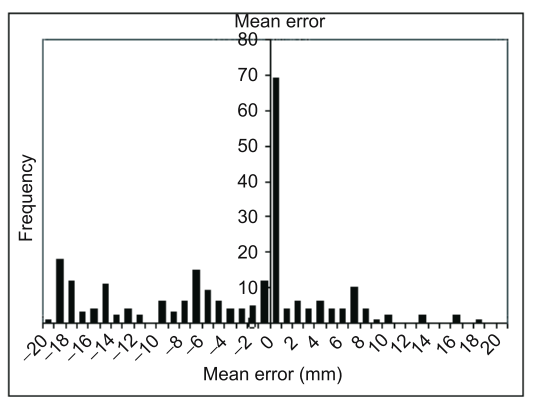

(c)

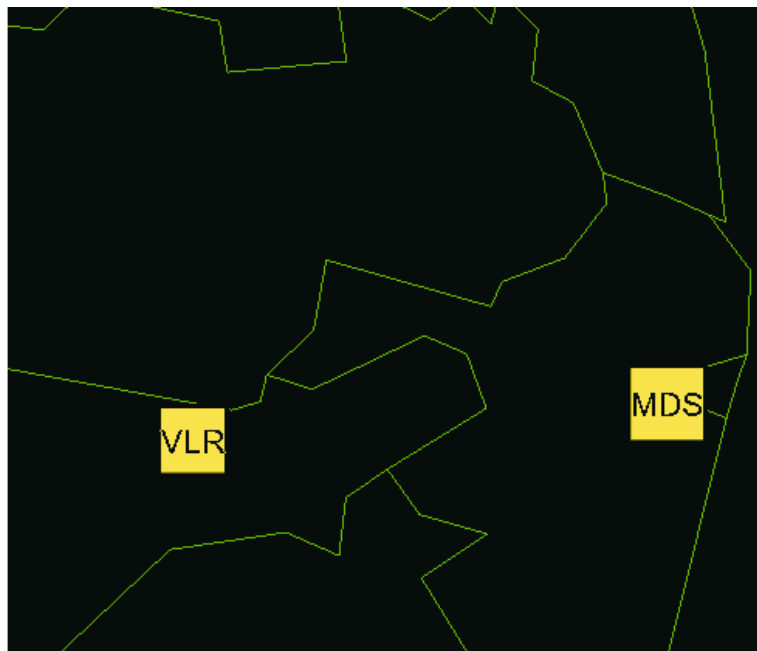

(b)

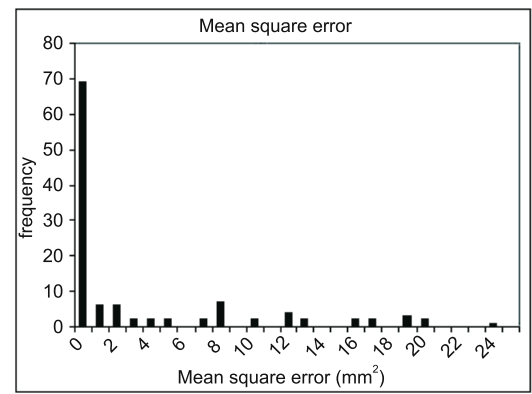

(d)

Figure 9. (a) Hourly accumulated rainfall by the multi-sensor precipitation algorithm of (Lakshmanan et al 2007); (b) location of two self-recording rain gauge stations located at Vellore and Madras; (c) mean error and (d) mean square error histograms for the $60 \mathrm{~min}$ accumulated rainfall by the self recording rain gauge compared to radar accumulations for the same period. The $\mathrm{x}$-axis gives the error in $\mathrm{mm}$ while the $\mathrm{y}$-axis gives the frequency of observations with the above error.

In this section various operational issues related to data collection strategies, networking, real-time analysis, shortcomings and operational constraints are discussed.

\subsection{Employing of predictable $V C P$}

The DWRs installed in India are currently being used for nowcasting of both mesoscale phenomena such as local thunderstorm events as well as large scale organized systems such as monsoon depressions or tropical cyclones. In view of the operational commitments, the radar stations have the following operational mandates:

- Creation of a rainfall input product - Surface Rainfall Intensity (SRI) based on $1 \mathrm{~km}$ CAPPI once in every 15 minutes.

- Tracking of cyclones as they approach the coast.

- Tracking and detection of mesoscale systems including localized thunderstorms.

This was being done by performing a longer range scan and an SRI scan separately. The scans were being interwoven to obtain good velocity measurements. The three scans were repeated at every 30 minutes.

On the other hand, for adequately utilizing the radar data to meet the nowcasting requirements, the scan strategy should have a long-range $(500 \mathrm{~km})$ reflectivity scan, a high unambiguous velocity (at least $20 \mathrm{~m} / \mathrm{s}$ ), should be able to sample every location every 5 to 10 minutes and should have consistent spatial and temporal resolution. However, on investigating the radar capabilities when trying to obtain above specifications, it is observed that the radar control software limits the speed, number of pulses, etc., automatically to keep within the capabilities of the radar. At long range of reflectivity, it was observed that the velocity data is poor (low Nyquist). Radar is not capable of good quality velocity data beyond $250 \mathrm{~km}$. The antenna is also not capable of rotating at a speed of more than $18 \mathrm{deg} / \mathrm{second}$. Antenna scan rate restriction arises only during Dual PRF operation, to ensure sufficient Dwell Time Pulses as imposed by the technique. Higher antenna rates are possible during single PRF operation. Further, 
Table 2. Scan strategy I for the DWRs operating in India.

\begin{tabular}{|c|c|c|c|c|c|c|c|c|c|c|}
\hline $\begin{array}{l}\text { Angle } \\
\left({ }^{\circ}\right)\end{array}$ & $\begin{array}{c}\text { Azimuth } \\
\text { rate } \\
(0 / \mathrm{s})\end{array}$ & $\begin{array}{l}\text { Period } \\
\text { (s) }\end{array}$ & $\begin{array}{l}\text { P.width } \\
\text { (usec) }\end{array}$ & $\begin{array}{c}\mathrm{PRF}(\mathrm{h}) \\
(\mathrm{Hz})\end{array}$ & $\begin{array}{c}\operatorname{PRF}(\mathrm{l}) \\
(\mathrm{Hz})\end{array}$ & $\begin{array}{c}\text { Dwell } \\
\text { (Pulse) }\end{array}$ & $\begin{array}{l}\text { Max. } \\
\text { range } \\
(\mathrm{km})\end{array}$ & $\begin{array}{l}\text { Range } \\
\text { step } \\
(\mathrm{km})\end{array}$ & $\begin{array}{c}\text { Clut. } \\
\text { (Filt.mps) }\end{array}$ & $\begin{array}{l}V_{\max } \\
(\mathrm{mps})\end{array}$ \\
\hline 0.5 & 18.0 & 20 & 2 & 300 & - & 16 & 500 & 0.5 & 1 & 7.8 \\
\hline 0.5 & 8.5 & 42.35 & 1 & 600 & 450 & 70 & 250 & 0.5 & 1 & 46.9 \\
\hline 1.5 & 18.0 & 20 & 2 & 300 & - & 16 & 500 & 0.5 & 1 & 7.8 \\
\hline 1.5 & 8.5 & 42.35 & 1 & 600 & 450 & 70 & 250 & 0.5 & 1 & 46.9 \\
\hline 2.5 & 8.5 & 42.35 & 1 & 600 & 450 & 70 & 250 & 0.5 & 1 & 46.9 \\
\hline 3.5 & 8.5 & 42.35 & 1 & 600 & 450 & 70 & 250 & 0.5 & 1 & 46.9 \\
\hline 5.0 & 8.5 & 42.35 & 1 & 600 & 450 & 70 & 250 & 0.5 & 1 & 46.9 \\
\hline 7.0 & 20.0 & 18 & 1 & 1000 & - & 50 & 150 & 0.5 & 1 & 26 \\
\hline 10.0 & 20.0 & 18 & 1 & 1000 & - & 50 & 150 & 0.5 & 1 & 26 \\
\hline 13.0 & 20.0 & 18 & 1 & 1000 & - & 50 & 150 & 0.5 & 1 & 26 \\
\hline 16.0 & 20.0 & 18 & 1 & 1000 & - & 50 & 150 & 0.5 & 1 & 26 \\
\hline 19.0 & 20.0 & 18 & 1 & 1000 & - & 50 & 150 & 0.5 & 1 & 26 \\
\hline
\end{tabular}

Table 3. Scan strategy II for the DWRs operating in India.

\begin{tabular}{|c|c|c|c|c|c|c|c|c|c|c|}
\hline $\begin{array}{l}\text { Angle } \\
\left({ }^{\circ}\right)\end{array}$ & $\begin{array}{c}\text { Azimuth } \\
\text { rate } \\
(0 / \mathrm{s})\end{array}$ & $\begin{array}{l}\text { Period } \\
\text { (s) }\end{array}$ & $\begin{array}{l}\text { P.width } \\
\text { (usec) }\end{array}$ & $\begin{array}{c}\operatorname{PRF}(\mathrm{h}) \\
(\mathrm{Hz})\end{array}$ & $\begin{array}{c}\mathrm{PRF}(\mathrm{l}) \\
(\mathrm{Hz})\end{array}$ & $\begin{array}{c}\text { Dwell } \\
\text { (Pulse) }\end{array}$ & $\begin{array}{l}\text { Max. } \\
\text { range } \\
(\mathrm{km})\end{array}$ & $\begin{array}{l}\text { Range } \\
\text { step } \\
(\mathrm{km})\end{array}$ & $\begin{array}{c}\text { Clut. } \\
\text { (Filt.mps) }\end{array}$ & $\begin{array}{l}V_{\max } \\
(\mathrm{mps})\end{array}$ \\
\hline 0.2 & 18.0 & 20 & 2 & 300 & - & 16 & 500 & 0.5 & 1 & 7.8 \\
\hline 0.2 & 8.5 & 42.35 & 1 & 600 & 450 & 70 & 250 & 0.5 & 1 & 46.9 \\
\hline 1.0 & 18.0 & 20 & 2 & 300 & - & 16 & 500 & 0.5 & 1 & 7.8 \\
\hline 1.0 & 8.5 & 42.35 & 1 & 600 & 450 & 70 & 250 & 0.5 & 1 & 46.9 \\
\hline 2.0 & 8.5 & 42.35 & 1 & 600 & 450 & 70 & 250 & 0.5 & 1 & 46.9 \\
\hline 3.0 & 8.5 & 42.35 & 1 & 600 & 450 & 70 & 250 & 0.5 & 1 & 46.9 \\
\hline 4.5 & 8.5 & 42.35 & 1 & 600 & 450 & 70 & 250 & 0.5 & 1 & 46.9 \\
\hline 6.0 & 8.5 & 42.35 & 1 & 600 & 450 & 70 & 250 & 0.5 & 1 & 46.9 \\
\hline 9.0 & 8.5 & 42.35 & 1 & 600 & 450 & 70 & 250 & 0.5 & 1 & 46.9 \\
\hline 12.0 & 8.5 & 42.35 & 1 & 600 & 450 & 70 & 250 & 0.5 & 1 & 46.9 \\
\hline 16.0 & 8.5 & 42.35 & 1 & 600 & 450 & 70 & 250 & 0.5 & 1 & 46.9 \\
\hline 21.0 & 8.5 & 42.35 & 1 & 600 & 450 & 70 & 250 & 0.5 & 1 & 46.9 \\
\hline
\end{tabular}

it is observed that there are problems with the radar power supply when high pulse repetition frequencies are used.

On the basis of above results, two new strategies are listed in tables 2 and 3 . While the first scan strategy ( 7.5 minutes per volume scan) was found applicable to short lived storms close to the radar, the latter scan strategy (10 minutes per volume scan), gave better results when the storms are longer lived and further away from the radar. The scan strategy II, initially started at the DWR at Machilipatnam as given in table 3 consists of a long-range $(500 \mathrm{~km})$ scan at low PRF for only $z$ at the lower two elevations, followed by shorterrange $(250 \mathrm{~km})$ scans at higher PRF for $z, V$ and sigma for all the elevations. The two were also combined within the Gematronik software using hybrid scan to create an SRI product. The scan strategy I, initially started at the DWR at Chennai, as given in table 2, was composed of three separate volume scans. It was fine-tuned to create low-PRF scans at the higher elevations so that vertical coverage is optimized. As may be seen in table 2, a hybrid scan from three different scans is achieved as well as dual PRF can be seen enabled partially in this scan strategy. The radar at Chennai was observed to hold both scan strategies without problem for long periods of time and both scan strategies have since been successfully applied to all the Doppler Weather radars of Gematronik make in India. However, it may be noted that operating the radar at the hybrid scan strategy I on a regular basis would result in duplication of files leading to faster diskoverflow and backup issues as well as high wearand-tear of the radar. Hence scan strategy II, which employs a double volume scan-one with dual PRF 
for all levels and the other for cyclone surveillance with two lowest elevations is commonly used by all radars. However, either of them can be used depending on the priority at that point of time.

\subsection{Real-time networking, data dissemination, tilt-by-tilt access}

For any nowcasting application, the radar data should be transmitted to the data-processing systems in real time. The time-series data (level I) is too voluminous to store/transmit. Hence there is a need to transmit radar moment data $(z, V$, sigma: raw data) and further dissemination of raw data from a central location to interested users. Moreover, for more lead time in nowcasting applications, it should also be possible to access the tiltby-tilt raw moment base data in real time. When data from various radars reach a central location in real time, it is necessary to organize the data so as to queue the data in sequence of the time of their reception from various radar sites. This data from multiple radars can also be combined together at a central location to provide mosaic data with large spatial coverage in earth projection, fused with NWP models, satellite data and data from other sensors, and delivered to interested users. Towards this end, a data manager (possibly using open-source LDM software and $56 \mathrm{~K}$ bandwidth line) may have to be used in the near future, to queue the data, as well as to redistribute it to various radar stations according to the requirement.

\subsection{Dissemination}

Regional nowcasting and analysis can be done at radar site. National nowcasting and analysis can be done at a central facility. For real-time mesoscale applications, DWR observations from DWR sites are required to be received online continuously at a central location (IMD New Delhi). This requires high bandwidth telecommunication connectivity. A TCP protocol is used to transfer the data from station to the central location at IMD headquarters. This protocol is preferred when applications cannot tolerate any loss and reordering of the data, as in the present case. Very recently all DWR stations along with Telecom Division of IMD, New Delhi have been connected by an IP VPN network. At each VPN access point/location, connectivity with the service provider of VPN network is through a wire, which is connected with modem at VPN location. Modem is connected with router which acts as a bridge between the VPN network and the local LAN. The router is connected with switch which connects the DWR servers among themselves as well as with the router. All the DWR stations, i.e., DWR Chennai, DWR Kolkata, DWR Visakhapatnam and DWR Machilipatnam are connected to VPN network with 512 kbps link. Since data from all the DWR stations will come to Telecom Division, New Delhi, so the Telecom Division, New Delhi is connected to VPN network with a higher bandwidth, i.e., 2 mbps link. One great advantage of VPN network is that all the VPN locations are connected with each other. So any two DWR stations can communicate with them. At every ten minutes interval, each DWR station uploads the six data files (for scan strategy 2) to the Telecom DWR FTP server at New Delhi. This server is mounted on another computer at the Northern Hemisphere Analysis Centre (NHAC) at IMD New Delhi. An interface software has been developed to convert the raw data into a desired hybrid scan of reflectivity, velocity and spectrum width in a standard format. Figure 10 displays the networking at IMD to receive DWR data in real time and disseminate the nowcasting products also in real time.

\subsection{Algorithms: India}

The WDSS-II algorithms were applied to the DWR data from one Indian radar at Chennai. Of the single radar algorithms, the newer multiple pass technique developed by Zhang and Wang (2006) successfully dealiased most of the highly folded velocity field, which the earlier Local Environmental Dealiasing (LED) scheme of Eilts and Smith (1990) was unable to detect. The neural networkbased quality control algorithm was also quite successful in detecting and removing the anomalous propagation echoes, in spite of being trained on NEXRAD radar data. It was, however, more successful in detecting the high reflectivity echoes, rather than the low reflectivity echoes from less intense convective cells. The SCIT and the MDA algorithms (part of the legacy SSAP suite of algorithms) too detected and successfully tracked the storm cells quite well through successive scans. However, this algorithm was applicable only to data with $1 \mathrm{~km}$ gatewidth. Hence higher resolution data at $0.6 \mathrm{~km}$ in the present case had to be down-sampled to apply the algorithm leading to a loss of substantial amount of information. The Azimuthal shear and divergence signatures were also found to be very useful, especially for locating the regions of development of new cumulus cells in mesoscale areas of convection. It was of less use for estimating the evolution of more large-scale organized systems, as in the present case for the main system.

While the single radar algorithms in polar coordinates were applied with a measurable degree of success, in the absence of collocated data from 


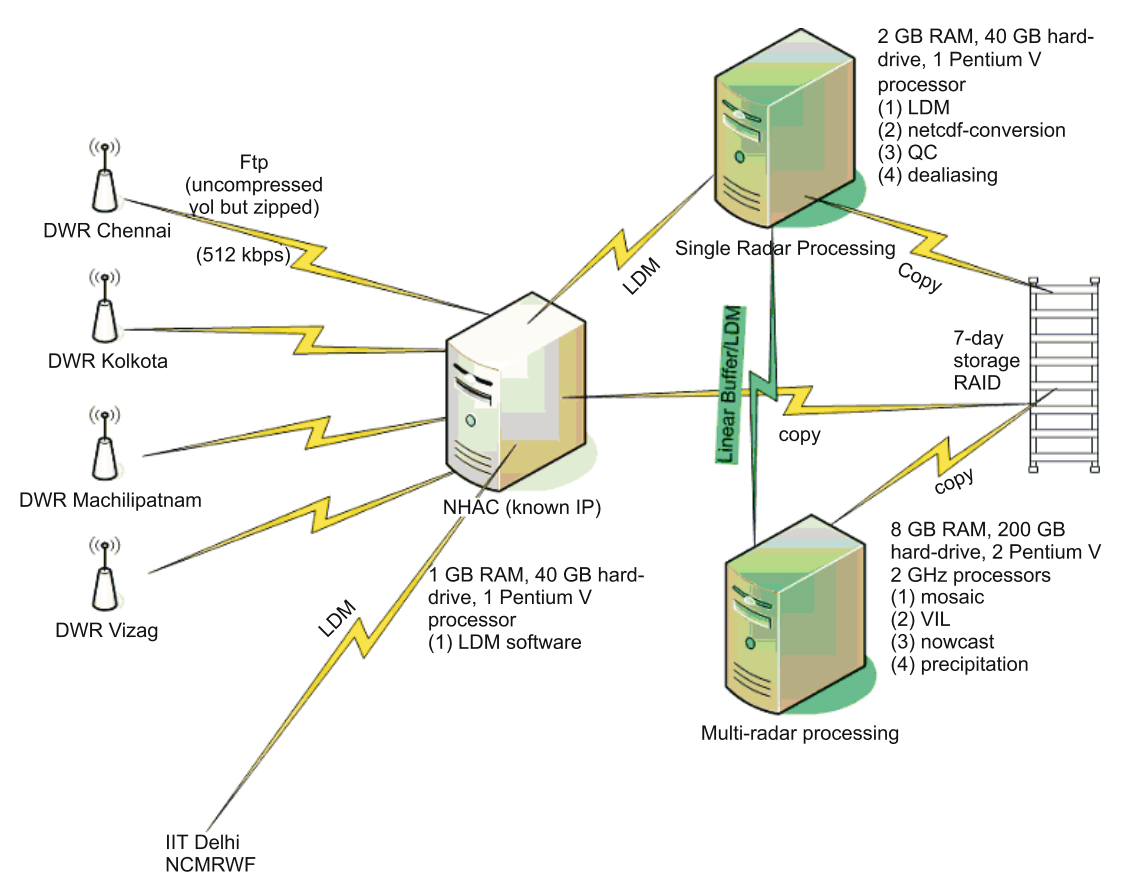

Figure 10. The radar data networking at IMD. The DWR data flow from the radar stations and the dissemination of nowcasting products is also displayed.

other DWRs with similar temporal and spatial resolution, the multiple radar algorithms did not generally provide any significant improvement in the nowcasting scenario. In many cases, the accuracy deteriorated, as in the case of the MRSSAP algorithm for storm cell detection and tracking. The forecast of the echo movement performed almost equally for both multi-sensor as well as single radar algorithms. The accuracy of estimate of the future intensity, position and organization in both instances was found to decrease significantly with the increase in the length of the forecast. Up to 30-minute forecast of echo movement and intensity was somewhat usable. Of course, it must be noted that an actual test of the potential of the multi-radar algorithms will be, only when data from multiple radars are integrated on a common platform. Hence, these algorithms need to be trained and tested on a larger dataset before it is usable in real time applications over India.

A significant source of error of the multisensor algorithms may be due to the default values used in the algorithms for the surface temperature, height of the freezing level and that of $-10^{\circ} \mathrm{C}$ and $-20^{\circ} \mathrm{C}$. These default values correspond to the mid-latitudinal values of the temperature profile and are much lower than those for the tropics. Hence, for more reliable operational implementation of the WDSS-II algorithms to various climate regimes, the default thresholds for various parameters should be adjustable by the user concerned.

While it is not advisable to make lasting recommendations for the scan strategy as well as the WDSS-II algorithms on the basis of a single case study, the implementation of many of these algorithms to the Indian DWR data and the resultant recommendations for improvement in the data quality may prove useful to other countries in the tropical regions, embarking on a DWR modernization program. This will help to provide a new insight into the structure and characteristics of such weather systems in this part of the world.

\section{Concluding remarks}

The main objective of this study has been, to test the applicability of WDSS-II algorithms in the processing of Indian DWR data for nowcasting of mesoscale aspects of the Bay of Bengal cyclone Ogni of October 2006. The present study makes a detailed analysis of various scan strategies to apply WDSS-II algorithms for quality control of DWR observations and generation of various nowcast products. The study demonstrated strength and limitations of the procedure for detecting and removing noise and ground/sea clutter, dealiasing of velocity and nowcasting applications such as, tracking of storm cells and mesocyclones through successive scans, reflectivity mosaic creation, rainfall estimation, etc., using Gematronik make DWR over Indian region. The quality controlled DWR data will be of great use to the NWP modelling community.

In respect of the cyclone Ogni, the task of processing DWR observations of Chennai has been 
successfully accomplished. However, most of the default values in various algorithms are customized for midlatitude conditions. Although the results are encouraging, various aspects of the software need to be customized to Indian conditions before making it fully operational. The study provides an in depth view of the structure of a tropical cyclone in this region of the world and makes a case for an improved disaster warning system for severe weather phenomena in India utilizing radar observations.

\section{Acknowledgements}

The study was initiated as a part of the collaboration work under the sub-project Local Severe Storm and Flash Floods of Climate Forecasting component of USAID Disaster Management Support Project. The first author is grateful to the Government of India for the kind approval of her deputation and to USAID/NOAA for funding the visit. The authors would like to thank Ms Nina Minka of USAID, Dr Robert Jubach and Ms Carolyn Corvington of NOAA and Mr Greg Austreng, Mr N M Prusty and Mr Balaji of USAID-IRG for constant support and co-operation at various stages to make the visit successful. Authors would like to thank AVM Dr Ajit Tyagi, DGM, IMD and Mr R C Bhatia, ADGM (retd.) for their encouragement, keen interest, valuable suggestions and providing all facilities to complete the work.

The authors would like to thank Ms Ami Arthur, Mr Joe Chrisman, Dr Tim Crum, Mr Kurt Hondl, Mr Kenneth Howard, Mr Charles Kerr, Mr Kevin Manross, M Kevin Scharfenberg, Mr Greg Stumpf, Mr Travis Smith, Mr Robert Toomey, Ms Rong Wan and Dr Jian Zhang at the National Severe Storms Laboratory, USA for extending all co-operation, useful discussions and necessary modifications to the algorithms to apply to Indian radar data and interpret the results. The authors would also like to thank Mr J P Gupta and the staff at CDR Chennai, Mr Y K Reddy, Mr Muthuramalingam and the staff at CDR Machilipatnam, Mr S K Kundu and Dr Hari Singh at IMD for promptly and with extraordinary effort making the radar data available in the right format at a very short notice for this application and also co-operating fully in applying the new VCPs to the DWR stations.

\section{References}

Barnes G 2001 Severe local storms in the tropics; In: Severe Convective Storms (eds) Charles A and Doswell III, AMS Meteorological Monograph Series 28(50) 359-432.
Eilts M D and Smith S D 1990 Efficient dealiasing of Doppler velocities using local environment constraints; J. Atm. Ocean Tech. 7(1) 118-128.

Fulton R A, Breidenback J P, Dong-Jun Seo, Miller D A and Bannon T O 1998 The WSR-88D rainfall algorithm; Wea. Forecasting 13 377-395.

India Meteorological Department; RSMC, Tropical Cyclones, New Delhi 2007 RSMC Report on Cyclonic Disturbances over North Indian Ocean during 2006; pp. $76-81$.

Johnson J, Mackeen P, Witt A, Mitchell E, Stumpf G, Eilts M and Thomas K 1998 The storm cell identification and tracking algorithm: An enhanced WSR-88D algorithm; Wea. Forecasting 13 263-276.

Kessinger C, Ellis S and Van Andel J 2003 The radar echo classifier: A fuzzy logic algorithm for the WSR-88D; Conference on Artificial Intelligence Applications to the Environmental Science, Amer. Meteor. Soc., Long Beach, CA P1.6 1-11.

Lakshmanan V, Hondl K, Stumpf G and Smith T 2003a Quality control of weather radar data using texture features and a neural network; 5th Int. Conf. on Adv. in Patt. Recogn., IEEE, Kolkata, 1-6.

Lakshmanan V, Rabin R and DeBrunner V 2003b Multiscale storm identification and forecast; J. Atm. Res. 67 367-380.

Lakshmanan V, Smith T, Stumpf G and Hondl K D 2007 The Warning Decision Support System Integrated Information; Wea. Forecasting 22 596-612.

Lynn R and Lakshmanan V 2002 Virtual radar volumes: Creation, algorithm access and visualization; 21st Conference on Severe Local Storms, Amer. Meteor. Soc., San Antonio, TX.

Marshall J S and Palmer W M 1948 The distribution of raindrops with size; J. Meteor. 5 165-166.

Rao G V, Santhanam K, Gallagher D, Scheck J W, Edwards R, Schaefer J T, Spratt S M and Hagemeyer B C 2003 Radar characteristics of mesocyclones associated with tropical cyclones and simulation of the mesocyclonic characteristics using MM5; Preprints, 10th. Conf. on Mesoscale Processes, Portland, P2.10.

Sinha V and Pradhan D 2006 Super-cell storm at Kolkata, India and neighbourhood - Analysis of thermodynamics conditions, evolution, structure and movement; Indian J. Radio Space Phys. 35 270-279.

Smith T M and Elmore K L 2004 The use of radial velocity derivatives to diagnose rotation and divergence; 11 th Conf. on Aviation, Range, and Aerospace, Amer. Meteor. Soc., Hyannis, MA, CDROM.

Srivastava Kuldeep, Roy Bhowmik S K, Sen Roy S, Thampi S B and Reddy Y K 2010 Simulation of high impact convective events over Indian region by ARPS model with assimilation of Doppler Weather Radar radial wind and reflectivity; Atmosfere 23(1) 53-74.

Stumpf G J, Smith T M and Gerard A E 2002 The multipleradar severe storm analysis program (MR-SSAP) for WDSS-II; Preprints, 21st Conf. on Severe Local Storms, San Antonio, TX, Amer. Meteor. Soc., 138-141.

Stumpf G J, Witt A, Mitchell E D, Spencer P L, Johnson J T, Eilts M D, Thomas K W and Burgess D W 1998 The National Severe Storms Laboratory Mesocyclone Detection Algorithm for the WSR-88D; Wea. Forecasting 13 304-326.

Stumpf G J, Marzban C and Rasmussen E 1995 The new NSSL mesocyclone detection algorithm: A paradigm shift in the understanding of storm-scale circulation detection; 27th Conference on Radar Meteorology 6A.3 208-210.

Suresh R 2007 Observations of sea breeze front and its induced convection over Chennai in southern peninsular 
India using Doppler Weather Radar; Pure Appl. Geophys. 164 1511-1525.

Zhang J, Howard K, Xia W, Langston C, Wang S and Qin Y 2004 Three-dimensional high resolution national radar mosaic; Preprints (CD-ROM), The 11th Conference on
Aviation, Range, and Aerospace Meteorology. Amer. Meteor. Soc., 4-8 October 2004, Hyannis, MA.

Zhang J and Wang S 2006 An Automated 2D Multipass Doppler Radar Velocity Dealiasing Scheme; J. Atm. Ocean. Tech. 23(9) 1239-1248.

MS received 24 February 2009; revised 2 January 2010; accepted 4 January 2010 